\title{
An elongate hadrosaurid forelimb with biological traces informs the biogeography of the Lambeosaurinae
}

\author{
Chase Doran Brownstein ${ }^{1,2 *}$ ( $)$ and Immanuel Bissell ${ }^{2}$ \\ ${ }^{1}$ Stamford Museum and Nature Center, Stamford, Connecticut <chasethedinosaur@gmail.com> \\ ${ }^{2}$ Yale University, New Haven, Connecticut <immanuel.bissell@yale.edu>
}

\begin{abstract}
Although the fossil record of the Late Cretaceous eastern North American landmass Appalachia is poor compared to that from the American West, it includes material from surprisingly aberrant terrestrial vertebrates that may represent relictual forms persisting in relative isolation until the end of the Mesozoic. One intriguing question is to what extent eastern and western North American faunas interspersed following the closure of the Western Interior Seaway during the Maastrichtian Stage of the Late Cretaceous ca. 70 Ma. Isolated remains from the Atlantic Coastal Plain in New Jersey have been preliminarily identified as the bones of crested lambeosaurine hadrosaurids, a derived clade known from the Cretaceous of Asia, western North America, and Europe, but have not been formally described. We describe the partial forelimb of a large hadrosaurid from the late Maastrichtian New Egypt Formation of New Jersey. The ulna preserves multiple deep scores identifiable as shark feeding marks, and both bones show ovoid and circular marks attributable to invertebrates. This forelimb is very similar to another partial antebrachium from the same area that shows evidence of septic arthritis. Both these specimens and a complete humerus from the same unit are closely comparable to the lower forelimbs of lambeosaurines among hadrosaurid dinosaurs. Although the absence of lambeosaurine synapomorphies observable on the New Egypt Formation forelimbs precludes their definite referral to Lambeosaurinae, they show that a morphotype of large hadrosauromorph with distinctly elongate forelimbs existed in the latest Maastrichtian of eastern North America and allow for a revision of the latest Cretaceous biogeography of crested herbivorous dinosaurs.
\end{abstract}

\section{Introduction}

During the Late Cretaceous, eastern and western North America were separated as the Western Interior Seaway, a shallow body of saline water, inundated the American interior. This isolated the vertebrate faunas of the west from the eastern landmass (Appalachia) formed from the continent. In contrast to the excellent, stratigraphically continuous record of terrestrial vertebrates known from the Upper Cretaceous of the American West, only a poor record exists for Appalachia (e.g., Langston, 1960; Gallagher, 1993, 1997; Schwimmer et al., 1993; Weishampel and Young, 1996; Schwimmer, 1997, 2002; Weishampel et al., 2004; Carr et al., 2005; Weishampel, 2006; Brusatte et al., 2011; Ebersole and King, 2011; Longrich, 2016; Prieto-Márquez et al., 2016a, b). Appalachia seems to have harbored a distinctive endemic terrestrial vertebrate fauna, exemplified by the discovery of aberrant, relictual dinosaurs such as the large-handed Maastrichtian non-tyrannosauroid tyrannosauroid Dryptosaurus (e.g., Brusatte et al., 2011) and the middle Campanian basal hadrosaurid Hadrosaurus foulkii Leidy, 1858 (Prieto-Márquez et al., 2006, 2016a, b). However, little is known about the faunal transitions in Appalachia that took place during and following the closure of the Western Interior Seaway in the Maastrichtian. Although there is evidence that western dinosaur clades migrated eastward

*Corresponding Author by the very end of this stage (Farke and Phillips, 2017), no distinctively western dinosaurs have been described from the Maastrichtian of the Atlantic Coastal Plain.

Reports of bones from the Atlantic Coastal Plain resembling those of lambeosaurines, a group of herbivorous dinosaurs in the nearly cosmopolitan clade Hadrosauridae that sported an array of bony head crests, have hinted at the possibility that some clearly foreign faunal components successfully migrated to the eastern coastline of North America by the Maastrichtian (e.g., Gallagher, 1993, 1997). However, these putative lambeosaurine occurrences have remained unsubstantiated. We describe the partial forelimb of a large hadrosaurid dinosaur from the New Egypt Formation, an uppermost Maastrichtian unit that directly underlies the K-Pg boundary in parts of New Jersey (e.g., Gallagher, 1993; Miller et al., 2004; Brusatte et al., 2011). Baird and Horner (1976) and Gallagher (1993, 1997) considered the forelimb, which was recovered from the same site as the holotypes of Dryptosaurus and "Hadrosaurus minor" Marsh, 1870 (e.g., Gallagher, 1993, 1997; Brusatte et al., 2011), to be from an indeterminate lambeosaurine, but no description of the specimen was provided. If this referral is true, it would be of major biogeographic importance because the Lambeosaurinae are known exclusively from Eurasia and western North America (e.g., Weishampel et al., 2004; Prieto-Márquez et al., 2012). The forelimb shows several important similarities to lambeosaurine hadrosaurids, although the absence of synapomorphies of that clade preclude a confident referral at this time. 


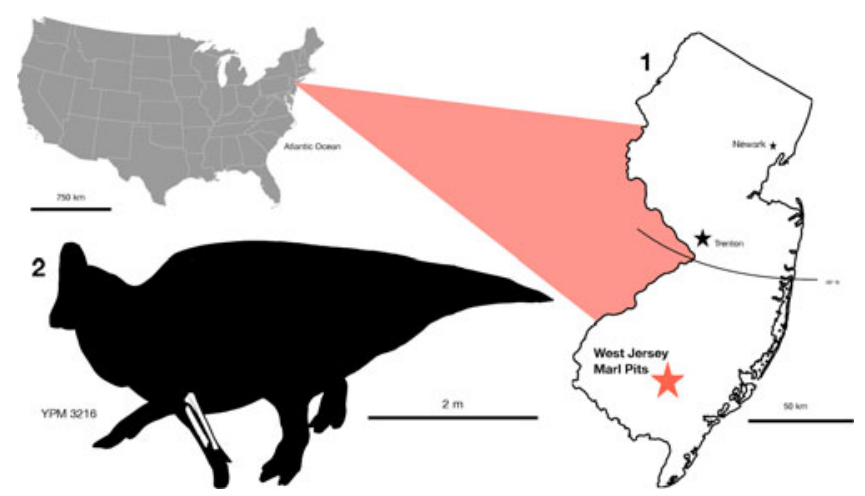

Figure 1. Locality Context and Skeletal. (1) Location of the site of discovery of YPM 3216; (2) reconstruction of YPM 3216 as a lambeosaurine dinosaur.

The partial forelimb, which consists of an associated radius and ulna, is littered with biological traces that show it was deposited along the sea floor of the Atlantic Ocean. These include circular traces identifiable as those of invertebrates, as well as deep, linear to ellipsoid grooves on the ulna characteristic of shark feeding traces on dinosaur and Mesozoic vertebrate bones (e.g., Everhart et al., 1995; Schwimmer, 1997; Schwimmer et al., 1997; Everhart, 1999; Shimada and Everhart, 2004; Shimada and Hooks, 2004; Everhart and Ewell, 2006; Schein and Poole, 2014; Hill et al., 2015). The forelimb provides another example of the bloat-and-float model for dinosaur deposition in oceans and seas, wherein the body would float out to sea and slowly decompose as it was scavenged by marine predators (e.g., Schwimmer, 1997, 2002; Davis and Briggs, 1998; Everhart and Ewell, 2006; Syme and Salisbury, 2014; Mallon et al., 2018).

\section{Geological setting}

The bones described in this paper were recovered from the former site of the West Jersey Company marl pits (Figure 1), which has also yielded the remains of the tyrannosauroid Dryptosaurus aquilunguis Cope, 1866 (e.g., Brusatte et al., 2011) and smallbodied hadrosauroids (e.g., Gallagher, 1993). All this material comes from the New Egypt Formation, an upper Maastrichtian unit in the Atlantic Coastal Plain that consists of dark gray and brown glauconitic clays and sands (Gallagher, 1993). Quartz is also present in minor quantities (Gallagher, 1993). The formation is 35 feet thick in Monmouth County surface exposures and increases to 90 feet as it moves towards the Atlantic coast, where it comfortably overlies the Navesink Formation (Olsson, 1989) and gradually thins as it moves farther south (Miller, 1956). In the upper section of the New Egypt Formation, sideritic mudstones and pockets of greensand are common (Olsson, 1989).

Macrofossils are diffuse in both the New Egypt and the Navesink formations, and usually consist of invertebrate material when present (Olsson, 1989; Gallagher, 1993). The lower portion of the New Egypt Formation preserves an assemblage of marine vertebrate and invertebrate remains, including gastropods such as Lunatia, Pyropsis, and Turitella, as well as the bivalves Exogyra costata Say, 1820, Crassatellites vadose
Morton, 1834, Cucullaea vulgaris Morton, 1830, Cardium sp., and Trachycardium (Gallagher, 1993; Miller et al., 2004). The ammonites Sphenodiscus lobatus (Tuomey, 1856) and Eubaculites carinatus (Morton, 1834) are also represented (Olsson, 1963). Fragments of the belemnite Belemnitella have been found in the lower New Egypt Formation, and Oleneothyris fragments are common in the upper half of the unit (Olsson 1963). Koch and Olsson (1977) and Gallagher (1993) reported an assemblage of larger marine vertebrates, including the panchelonioid turtle Toxochelys atlantica (Zangerl, 1953) and Mosasaurus maximus Cope, 1869, from the New Egypt Formation. The small-bodied mosasaur Halisaurus platyspondylus Marsh, 1869 is also known from several specimens from the New Egypt Formation, including a well-preserved partial skull and jaws (Polycn and Lamb, 2012).

\section{Material}

Repositories and institutional abbreviation.-YPM, Yale Peabody Museum, New Haven, CT, USA.

\section{Systematic paleontology}

\author{
Dinosauria Owen, 1842 \\ Ornithischia Seeley, 1888 \\ Ornithopoda Marsh, 1881 \\ Hadrosauroidea Cope, 1870 \\ Hadrosauridae Cope, 1870 \\ Hadrosauridae indet. \\ Figures 2, 3
}

Occurrence.-West Jersey Co. Marl Pits, New Jersey, USA. The material is from the Maastrichtian (ca. $66 \mathrm{Ma}$ ) New Egypt Formation, which underlies the K-Pg transition (e.g., Gallagher, 1993; Miller et al., 2004).

\section{Description.-}

Radius.-The radius (Fig. 2.1-2.4) is only known from a portion of the shaft, but was clearly elongate and straightened (Fig. 2.1, 2.4) as in most other hadrosaurids (e.g., Parks, 1919; Pinna, 1979; Godefroit et al., 2001, 2004, 2012a; PrietoMárquez et al., 2006, 2013; Evans and Reisz, 2007; Senter, 2012; Prieto-Márquez, 2014; Anné et al., 2016; Kobayashi et al., 2019). This bone is $339 \mathrm{~mm}$ long as preserved, with a midshaft circumference of $139 \mathrm{~mm}$. The bone shaft (Fig. 2) clearly shows the radius was more elongate than in non-hadrosaurid hadrosauromorphs such as Gilmoreosaurus (Prieto-Márquez and Norell, 2010), Gobihadros (Tsogtbaatar et al., 2019), Bactrosaurus (Gilmore, 1933), or Eolambia (McDonald et al., 2012). An elongate radius is found in most lambeosaurine dinosaurs (e.g., Brown, 1913; Parks, 1931; Godefroit et al., 2001, 2004; Evans and Reisz, 2007; Senter, 2012). Given the circumference of the bone, the length of the preserved shaft portion, which does not show proximal or distal expansion, suggests the radius was similar in robustness to the preserved ulna when complete (Figs. 2, 3). This condition contrasts with the antebrachia of most saurolophine hadrosaurids, in which the ulna is considerably more robust than the radius and widens 


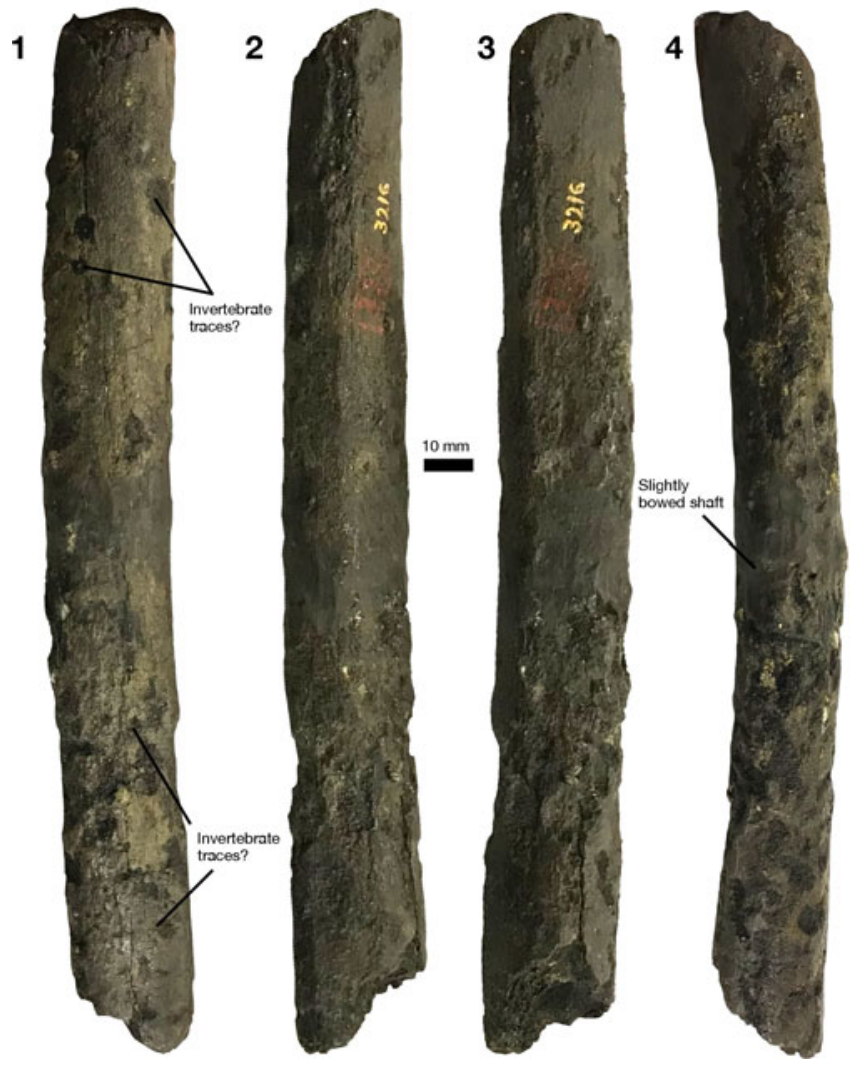

Figure 2. Hadrosauridae indet. YPM 3216. Radius in (1) lateral, (2) dorsal, (3) ventral, and (4) medial views. Courtesy of the Division of Vertebrate Paleontology; Peabody Museum of Natural History, Yale University, New Haven, Connecticut, USA; peabody.yale.edu.

proximally (e.g., Parks, 1919; Pinna, 1979; Godefroit et al., 2012b; Senter, 2012; Prieto-Márquez, 2014; Kobayashi et al., 2019).

The radius is slightly more worn than the associated ulna (Figs. 2, 3), and preserves several circular and nearly circular depressions and scars along its shaft that may be attributable to biological trace-makers. It is well established in the paleontological literature that following post-mortem deposition at sea, dinosaur bones would often go through extensive biological weathering (e.g., Carpenter et al., 1995; Everhart et al., 1995; Schwimmer, 1997; Schwimmer et al., 1997; Everhart, 1999; Schein and Poole, 2014). The traces that appear on the radius described in this contribution are identifiable as biological based on their clearly circular shape and deepened center, and are similar to "macroborings" found on other marine material (Wilson, 2007). These circular borings are especially concentrated along the center of the radius shaft, and indicate this surface of the bone was exposed to invertebrate trace-makers (e.g., Bromley and Heinberg, 2006). These traces also compare somewhat favorably with the circular, radially symmetrical barnacle scars present on the fossilized bones of many types of marine reptiles (e.g., Martill, 1987; Buckeridge, 2011; Janssen et al., 2013).

Ulna.-The ulna (Fig. 3.1-3.6) is completely preserved and possesses a less-eroded bone surface than the radius. The ulna is elongate as in other hadrosaurids, but considerably more gracile than the corresponding element in other taxa (e.g., Brown, 1913; Parks, 1919, 1922, 1923; Pinna, 1979;
Godefroit et al., 2001, 2004, 2012a, b; Prieto-Márquez et al., 2006, 2013; Evans and Reisz, 2007; Senter, 2012; PrietoMárquez, 2014; Anné et al., 2016; Kobayashi et al., 2019), with the exception of many hadrosauromorphs (e.g., Gilmore, 1933; Dalla Vecchia, 2009; Prieto-Márquez and Norell, 2010; McDonald et al., 2012; Tsogtbaatar et al., 2019). The ulna gently expands proximally in anterior and posterior views. One lambeosaurine specimen from Europe is notable for having especially gracile ulnae over ten times as long as dorsoventrally wide (Conti et al., 2020), which is the condition in YPM 3216.

This bone is $624 \mathrm{~mm}$ long, $107 \mathrm{~mm}$ wide mediolaterally, $81 \mathrm{~mm}$ wide anteroposteriorly at its proximal end, and $149 \mathrm{~mm}$ in midshaft circumference. The olecranon process is reduced, whereas the medial proximal process is heavily expanded to form a distinct, triangular expansion of bone that begins to diverge from the ulnar shaft at approximately one-third of the proximodistal run of the bone. Proximally, the medial process suddenly diverges more strongly from the main bone shaft. The divergence of the medial process from the ulnar shaft remains relatively constant in saurolophine hadrosaurids, where it is also more heavily developed (e.g., Brown, 1913; Godefroit et al., 2012a; Senter, 2012; Campione, 2014; PrietoMárquez, 2014). The medial process does not expand more proximally than the lateral process. These processes form the borders of the articular facet for the radius, which is broadly arcuate in proximal view and produces a distinctively symmetrical, "T-shaped" proximal surface on the ulna. The "T-shaped" outline of the proximal ulna (Fig. 3.5) is less symmetrical in specimens of saurolophine hadrosaurids such as Edmontosaurus (Senter, 2012), although the condition varies due to preservation (see illustrations in Senter, 2012; Campione, 2014). The bone surface in the proximal articular facet for the radius contains numerous, developed striations that run parallel to the long axis of the ulna and form a ligament attachment site (e.g., Godefroit et al., 2012a).

The ulnar shaft is straightened in anterior, posterior, lateral, and medial views (Fig. 3.1-3.4). This is similar to the condition in most lambeosaurinine lambeosaurines, wherein the ulna is elongate and straightened (e.g., Brown, 1913; Godefroit et al., 2012b; Fig. 4) rather than gently bowed as in saurolophines (Godefroit et al., 2012b; Senter, 2012; Campione, 2014; PrietoMárquez, 2014) or shortened and robust as in parasaurolophines (Parks, 1922) and Amurosaurus (Godefroit et al., 2004). The buttressing surface for the radius on the distal ulna gently curves towards the medial margin of the bone, whereas the distal end of the ulna is slightly displaced laterally. This morphology matches the lambeosaurine condition more than the saurolophine one, where the radius and ulna are separated for most of their proximodistal run (e.g., Brown, 1913; Senter, 2012). The distal articular facet for the radius is slightly developed, as in other hadrosaurids (e.g., Brown, 1913; Parks, 1919, 1922, 1923; Pinna, 1979; Godefroit et al., 2001, 2004, 2012a, b; PrietoMárquez et al., 2006, 2012, 2013; Senter, 2012; PrietoMárquez, 2014; Anné et al., 2016; Kobayashi et al., 2019). In distal view, the ulna is subrectangular.

The presence of well-preserved ligament attachments on the ulna, along with the presence of smooth, original bone surface on the element, suggests this bone was minimally exposed to biotic and abiotic wear following its deposition at the bottom 
1

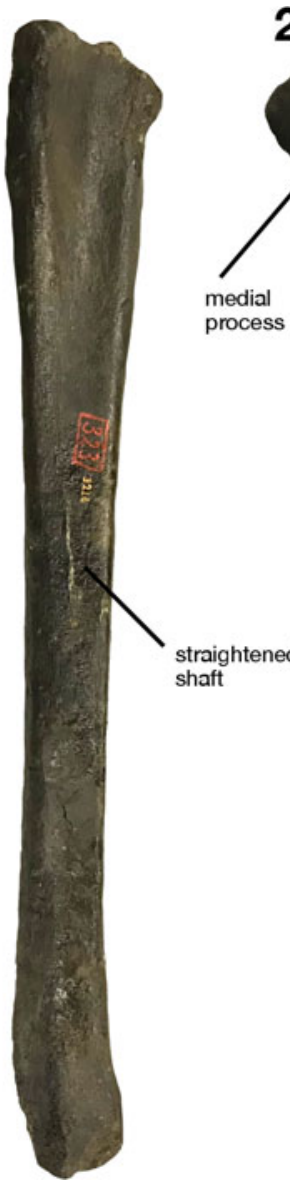

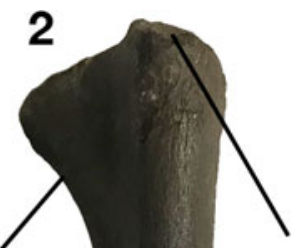
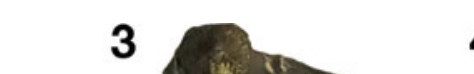

4

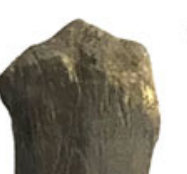

5

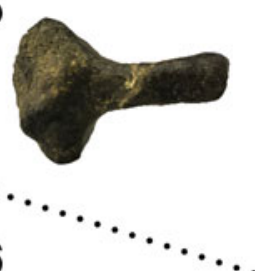

acromion

lateral process

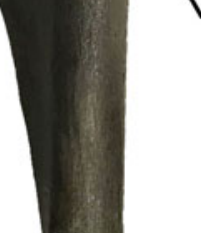

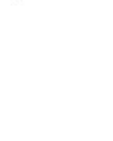

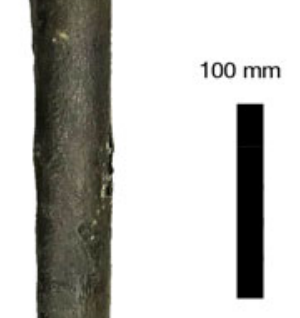

$100 \mathrm{~mm}$
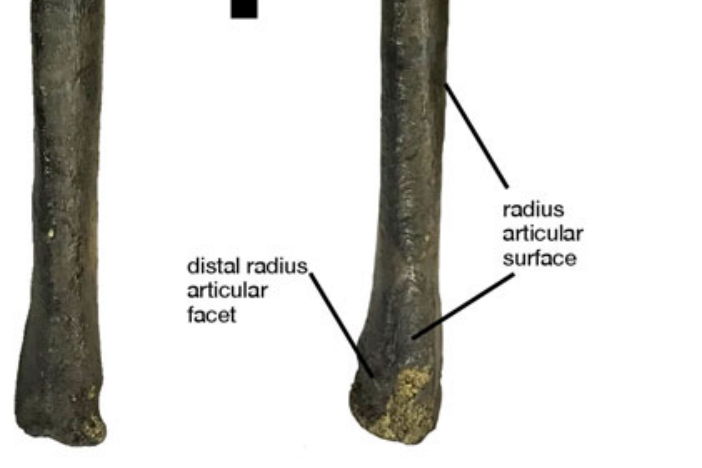

Figure 3. Hadrosauridae indet. YPM 3216. Ulna in (1) lateral, (2) dorsal, (3) ventral, (4) medial, and (5) proximal views, with a closeup (6) of the shark traces on the specimen. Courtesy of the Division of Vertebrate Paleontology; Peabody Museum of Natural History, Yale University, New Haven, Connecticut, USA; peabody.yale.edu.

of the Atlantic. One intriguing feature present on the external surface of the bone is a series of nearly parallel linear to slightly ellipsoid and straight to gently arched deep scores penetrating the lateral face of the specimen. A total of nine of these can be easily seen, although more may actually be present (Fig. 2.6). Each was clearly made by an individual tooth or tooth cusp, and all scores are oriented parallel to one another. They vary very slightly in maximum length and diameter, the larger ones approaching $20 \mathrm{~mm}$ in the former dimension.

Previous studies have attributed closely similar grooves on other dinosaur and vertebrate fossils to sharks based on the presence of shed shark teeth in bones bearing these distinctive grooves (e.g., Everhart et al., 1995; Schwimmer, 1997; Shimada and Everhart, 2004; Everhart and Ewell, 2006; Schein and Poole, 2014). The scores on the ulna, which are identical to definite shark feeding traces on other dinosaur bones from eastern North America (e.g., Schwimmer, 1997; Schwimmer et al., 1997) do not display identifiable grooves running perpendicular to their long axes, suggesting the sharks that made the traces lacked serrated dentition and therefore were not individuals of the genus Squalicorax, which are commonly found in the Maastrichtian units of the Atlantic Coastal Plain (e.g., Gallagher, 1993; Schein and Poole, 2014). The goblin shark Scapanorhynchus texanus (Roemer, 1849) is also a less likely candidate for the identity of the trace-maker, given that the morphology of the grooves suggests the teeth of the trace-maker or tracemakers were blade-shaped and not tall and thin as in the mesial teeth of that taxon. Furthermore, the estimated sizes of individuals of the Scapanorhynchus and the shark Odontaspis (also known from uppermost Maastrichtian-lowermost Danian sites in New Jersey) (Gallagher et al., 1986; Gallagher, 1993; Schein and Poole, 2014) do not match with the size of the traces, which clearly came from large sharks based on their length and width. Among the species reported from the Maastrichtian of the Atlantic Coastal Plain, the taxon Cretalamna appendiculata Agassiz, 1835 is considered the most likely candidate trace maker, although any precise identification is certainly tentative (see Schein and Poole, 2014).

Material.-YPM (Yale Peabody Museum) 3216, the associated complete ulna and partial radius of a large hadrosaurid dinosaur.

Morphometric analysis.-In order to further assess the referral of YPM 3216 to a lambeosaurine rather than saurolophine hadrosauroid, we used a discriminant analysis assessing the similarity of the New Jersey specimen to other hadrosaurid forelimbs using the program P.A.S.T. v. 3.18 (Hammer et al., 2001). A previously published dataset of hadrosauroid radius 

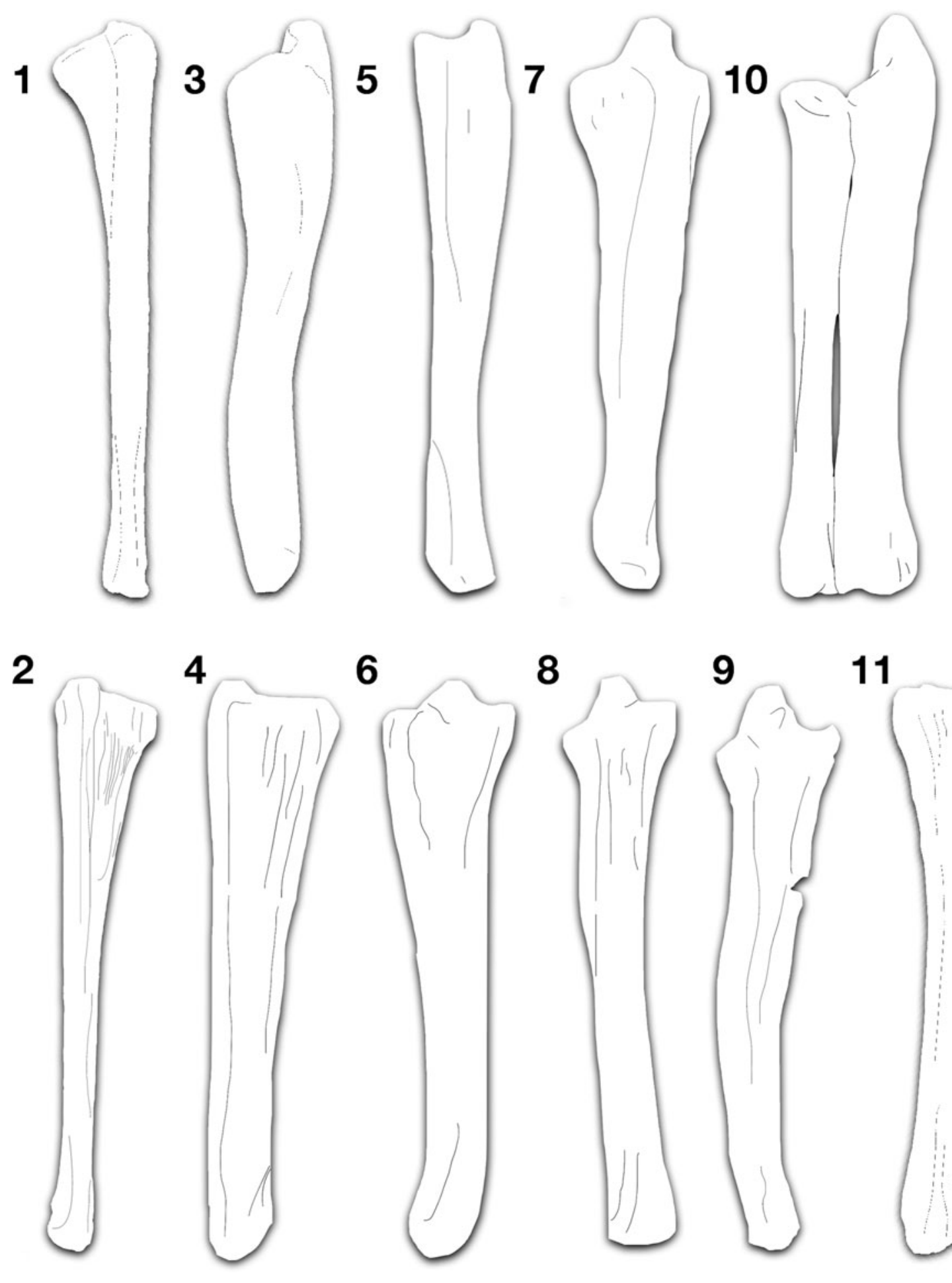

$6 \quad 8$

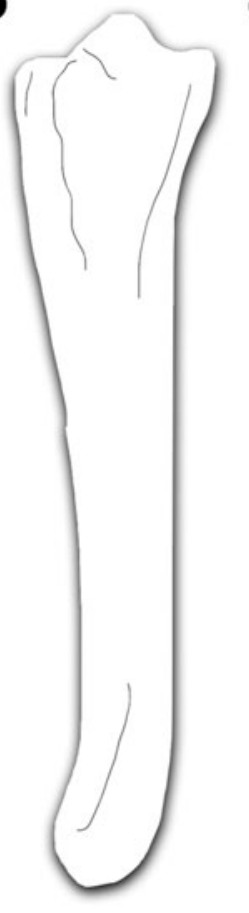

8

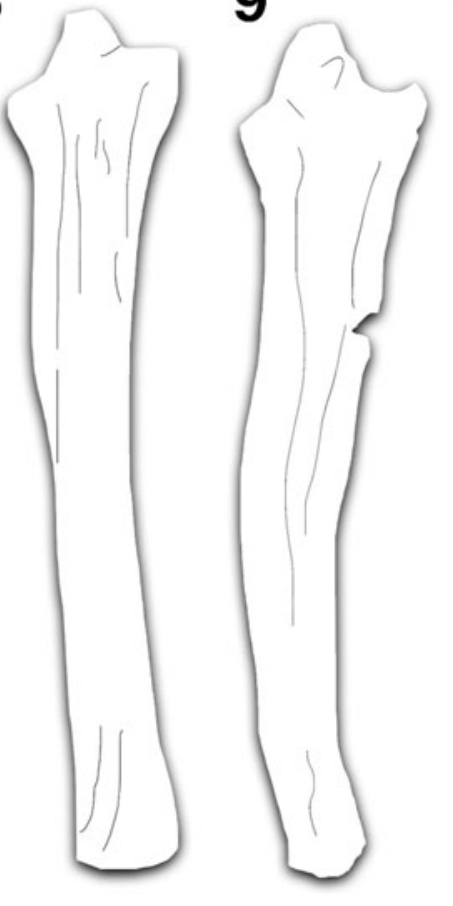

11

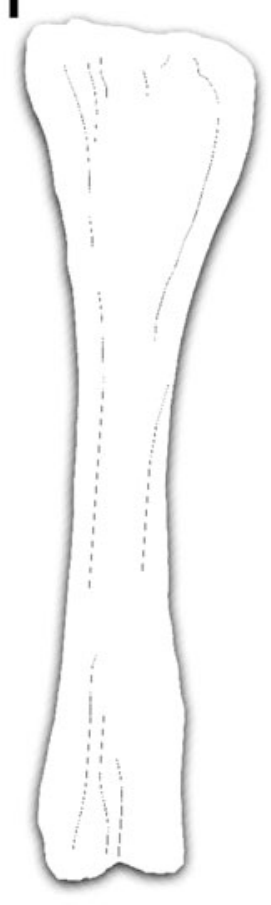

Figure 4. Comparison of hadrosaurid forelimbs. Ulnae of (1, 2) Hadrosauridae indet. YPM 3216, (3, 6) Amurosaurus riabinini (after Godefroit et al., 2004), (4) Olorotitan arharensis (after Godefroit et al., 2012a), (5, 8) Kundurosaurus nagornyi (after Godefroit et al., 2012b), Edmontosaurus regalis (7, 9), (10) Hypacro-

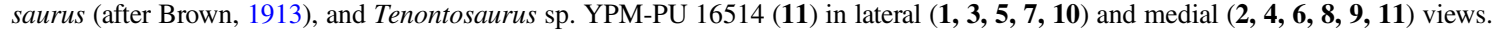

and ulna dimensions (Maidment et al., 2012) was used for this analysis. The matrix of Maidment et al. (2012) was modified to include measurements of the radii and ulnae of only specimens assignable to particular hadrosauromorph taxa. We also removed the small juvenile Maiasaura specimen included in the original dataset to reduce the potentially confounding effects of ontogenetic differences in long bone dimensions on the results. The discriminant analysis of ulna proportions in members of the Hadrosauromorpha $(\mathrm{N}=27)$ classified YPM 3216 with Hypacrosaurus (Fig. 5; Table 1), a CampanianMaastrichtian age lambeosaurine from western North America (e.g., Weishampel et al., 2004). 


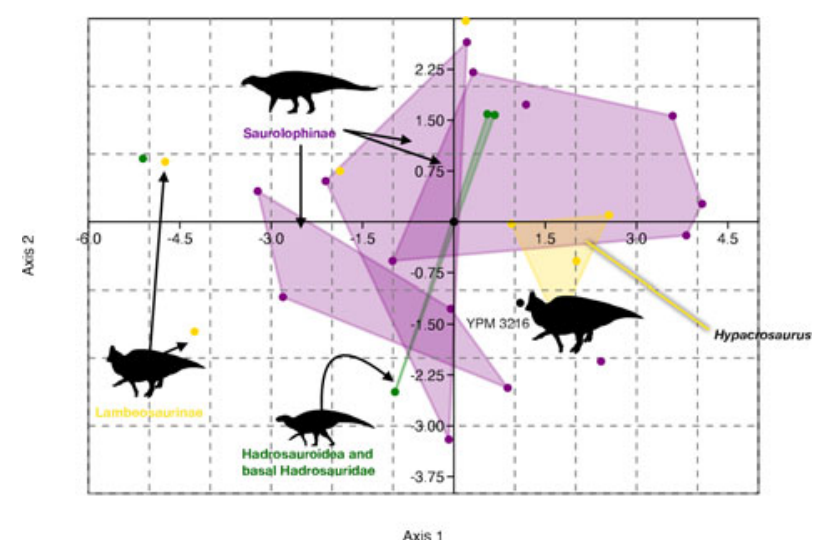

Figure 5. Discriminant analysis of hadrosauromorph ulnae with Hadrosauridae indet., YPM 3216, included.

Table 1. Loadings for the discriminant analysis of hadrosauromorph ulna proportions after Maidment et al. (2012). B = ulna length; $\mathrm{C}=$ Anteroposterior width of the ulna; $\mathrm{D}=$ mediolateral width.

\begin{tabular}{lccc}
\hline & Axis 1 & Axis 2 & Axis 3 \\
\hline B & 58.149 & -4.9678 & 29.19 \\
C & 7.3135 & 4.3264 & 15.629 \\
D & 11.255 & 6.1442 & 5.2687 \\
\hline
\end{tabular}

Remarks.-YPM 3216 is a hadrosaurid forelimb that resembles those of lambeosaurines more than saurolophines in the similar shaft circumferences of the radius and ulna, the strongly "T-shaped" outline of the proximal ulna, the close appression of the bones of the antebrachium, and the absence of a heavily developed medial process on the ulna that creates a distinct eminence along the shaft. A number of these features are apparent on the hadrosauromorph ulnae shown in Figure 3. The comparability of YPM 3216 to lambeosaurine forelimbs is also substantiated by the results of the phylogenetic and morphometric analyses conducted, which show YPM 3216 is referable to Hadrosauridae and compares most closely to lambeosaurines among hadrosaurids in the dimensions of the ulna included in that specimen.

\section{Discussion}

The results of firsthand comparisons with other hadrosauromorph forelimbs and the morphometric analysis conducted posit a hadrosaurid, and possibly lambeosaurine, identity for the radius and ulna. Previously, YPM 3216 was identified as a lambeosaurine forelimb by Gallagher (1993, 1997), as were the humerus ANSP 15550 and the radius and ulna NJSM 11961. NJSM 11961 preserves extensive pathologies consistent with septic arthritis (Anné et al., 2016). These pathologies heavily distort the morphology of the articular surfaces of the radius and ulna, meaning that comparison of these potentially taxonomically important areas in that specimen with the same areas on the radii and ulnae of other hadrosaurids is impossible. Therefore, we regard the identification of this specimen as the forelimb of a lambeosaurine by Gallagher (1993) as tenuous. We note that NJSM 11961 does include a clearly very elongate radius and ulna, which is closely comparable to the condition in
YPM 3216. The humerus ANSP 15550 is similar to lambeosaurines in its expanded deltopectoral crest (Gallagher, 1997), and was assigned to this clade by Weishampel et al. (2012).

Material compared with Lambeosaurus has been identified and reported from the Campanian-Maastrichtian of the Arctic in Nunavut, Canada (Vavrek et al., 2014). However, most of the Nunavut hadrosaurid material is highly fragmentary, and so it is difficult to argue for its assignment to more inclusive clades than Hadrosauridae (e.g., Vavrek et al., 2014). Only a single caudal centrum from the Nunavut collection has been the subject of detailed description (Vavrek et al., 2014). This bone is assignable to Hadrosauridae, but Vavrek et al. (2014) did not assign it to an indeterminate lambeosaurine. Resultantly, YPM 3216 is the best-characterized possible lambeosaurine specimen from the Maastrichtian of eastern North America.

Given the lack of lambeosaurine material known from the Maastrichtian of the American West (e.g., Weishampel et al., 2004), the forelimb described here is also important for providing a potential record of this clade at a time when they were generally rare on the North American continent. Although Asia and Europe harbored a high diversity of lambeosaurines throughout the end of the Cretaceous (e.g., Godefroit et al., 2001, 2004, 2012a; Weishampel et al., 2004; Prieto-Márquez et al., 2013), the record of this clade in the well-documented Maastrichtian units of the American West consists of a number of possible indeterminate specimens (e.g., Weishampel et al., 2004), with a notable absence of diagnostic material (Godefroit et al., 2001). The derived lambeosaurine Hypacrosaurus altispinus, known from the Campanian-Maastrichtian Horseshoe Canyon Formation of Alberta (e.g., Weishampel et al., 2004) is the best-characterized member of this group known from the American West that survived into the last stage of the Cretaceous. The presence of possible lambeosaurine forelimb material from the Maastrichtian Atlantic Coastal Plain is therefore all the more important, suggesting that, while uncommon, this group might have persisted in the Americas up to the K-Pg boundary. The reduction in lambeosaurine diversity during the Maastrichtian corresponds to the extinction of the Centrosaurinae, the dominant clade of the horned ceratopsians, during the approximately the same period (e.g., Brown and Henderson, 2014). Although recognition of the Lambeosaurinae in eastern North America must wait for the recovery of more complete specimens, the forelimb described in this contribution suggests the occurrence of this group along the Maastrichtian Atlantic coastline must be considered when biogeographic scenarios for the Hadrosauridae are proposed.

The possibility that the partial hadrosaurid forelimb described in this contribution belongs to a lambeosaurine has drawn us to consider what evidence there is for cross-continental dinosaur migration in the end-Cretaceous of North America. Previously, a single fossilized tooth from the Maastrichtian Owl Creek Formation of Mississippi was referred to a derived ceratopsid ceratopsian by Farke and Phillips (2017). This single element shows that large ceratopsians successfully dispersed into what would have been the eastern margin of the Western Interior Seaway by the Maastrichtian (Farke and Phillips, 2017). The presence of lambeosaurines on the eastern seaboard would suggest elements of western faunas were able to reach the edge of the continent, and would provide more evidence for 
large-scale, east-west dispersals than that given by the Mississippi ceratopsian tooth. Lambeosaurines themselves were a key component of the diverse megaherbivore assemblages during the Late Cretaceous in Asia, Europe, and western North America (e.g., Weishampel et al., 2004; Prieto-Márquez et al., 2013), although they seem to have undergone a significant decrease in their diversity during the Maastrichtian in the American West (e.g., Weishampel et al., 2004) along with other dinosaur groups such as the centrosaurine ceratopsians (Brown and Henderson, 2014) and the albertosaurine tyrannosaurids (e.g., Brusatte and Carr, 2016). Although the terrestrial fossil record of Appalachia is poor for the entirety of the Late Cretaceous, all diagnostic pre-Maastrichtian hadrosauromorph materials currently described from the landmass are from genera situated near the root of Hadrosauridae (e.g., PrietoMárquez et al., 2006, 2016a, b), and most indeterminate materials do not compare favorably enough with lambeosaurines to warrant consideration that they are potentially referable to this group (see the catalog of specimens in Gallagher, 1993). Despite the relatively incomplete hadrosauromorph record from Appalachia, it seems likely that any lambeosaurine records from the latest Maastrichtian Atlantic Coastal Plain represent genuine evidence of a Late Cretaceous eastward migration of this clade.

The presence of many examples of biological traces on the radius and ulna described in this paper adds to the welldocumented record of bio-eroded dinosaur bones from the American East. Previously, biological traces have been described from the remains of indeterminate theropods (e.g., Schwimmer, 2002; Brownstein, 2018) and hadrosauroids (e.g., Carpenter et al., 1995; Schwimmer, 1997; Schein and Poole, 2014). The record described here includes some of the best examples of shark feeding traces on dinosaur bones from the Maastrichtian of North America. The bone surface of the ulna is exquisitely preserved compared to other Maastrichtian-age hadrosaurid material from the Atlantic Coastal Plain (e.g., Schein and Poole, 2014), and shows that the bloat-and-float model of dinosaur bone preservation, wherein bones from the extremities of a bloated carcass floating on the surface of the water column would slowly come loose and fall to the sea floor, holds for some of the dinosaur material recovered from the West Jersey Marl Pit Company site. Given that the bones of Dryptosaurus (Brusatte et al., 2011) and other hadrosauromorphs from the same site (Brownstein, 2020) possess heavily abraded surfaces, the documentation of these definite biological traces on YPM 3216 is important for understanding the taphonomy of this unusually productive dinosaur site.

\section{Conclusions}

YPM 3216, a partial hadrosaurid forelimb consisting of a radius and ulna, is the best-characterized specimen of those potentially assignable to lambeosaurines from the eastern half of North America. The radius preserves biological traces assignable to marine invertebrates, whereas the ulna bears a multitude of deep scores identifiable as shark bite marks. The specimen supports the presence of a distinctive morphotype of long-armed, potentially lambeosaurine hadrosaurid along the latest Cretaceous Atlantic coastline.

\section{Author contributions}

C.D.B. examined and described the specimens, and wrote the introduction, results, and discussion sections, and conducted the morphometric analysis. I.B. researched the geological setting of the bones and wrote the geology section. C.D.B. and I.B. edited drafts of the paper.

\section{Acknowledgments}

We would like to thank D. Brinkman for granting C.D.B. access to the Yale Peabody Museum collections, and E. Lagos for help on performing a phylogenetic analysis included in a previous draft of this paper. Finally, we thank the editor H.-D. Sues, the associate editor D. Varricchio, and several anonymous reviewers for their comments, which greatly improved this paper.

\section{Accessibility of supplemental data}

Data available from the Dryad Digital Repository: https://doi. org/10.5061/dryad.t4b8gtj07

\section{References}

Agassiz, L., 1835, Rapport sur les poissons fossiles découverts en Angleterre: Neuchatel, Imprimerie de Petitpierre et Prince, $72 \mathrm{p}$.

Anné, J., Hedrick, B.P., and Schein, J.P., 2016, First diagnosis of septic arthritis in a dinosaur: Royal Society Open Science, v. 3(8), 160222. https://doi.org/ 10.1098/rsos.160222.

Baird, D., and Horner, J.R., 1976, A fresh look at dinosaurs of New Jersey and Delaware: Bulletin of the New Jersey Academy of Science, v. 22, p. 50.

Bromley, R.G., and Heinberg, C., 2006, Attachment strategies of organisms on hard substrates: a palaeontological view: Palaeogeography, Palaeoclimatology, Palaeoecology, v. 232 (2-4), 429453. DOI: 10.1016/ j.palaeo.2005.07.007

Brown, B., 1913, A new trachodont dinosaur, Hypacrosaurus, from the Edmonton Cretaceous of Alberta: Bulletin of the American Museum of Natural History, v. 32, p. 395-406.

Brown, C.M., and Henderson, D.M., 2014, A new horned dinosaur reveals convergent evolution in cranial ornamentation in Ceratopsidae: Current Biology, v. 25, p. 1641-1648.

Brownstein, C.D, 2018, The biogeography and ecology of the Cretaceous non-avian dinosaurs of Appalachia: Palaeontologia Electronica v. 21.1.5A, p. 1-56. https://doi.org/10.26879/801.

Brownstein, C.D, 2020, Osteology and phylogeny of small-bodied hadrosaurmorphs from an end-Cretaceous marine assemblage: Zoological Journal of the Linnean Society, zlaa085. https://doi.org/10.1093/zoolinnean/ zlaa085.

Brusatte, S.L., Benson, R.B., and Norell, M.A., 2011, The anatomy of Dryptosaurus aquilunguis (Dinosauria: Theropoda) and a review of its tyrannosauroids affinities: American Museum Novitates, no. 3717, p. 1-53.

Brusatte, S. L., and Carr, T.D., 2016, The phylogeny and evolutionary history of tyrannosauroid dinosaurs: Scientific Reports 6, 20252. https://doi.org/10. 1038/srep20252.

Buckeridge, J.S., 2011, Taphonomy and systematics of a new Late Cretaceous verrucid barnacle (Cirripedia, Thoracica) from Canterbury, New Zealand: Palaeontology, v. 54, p. 365-372.

Campione, N.E. 2014. Postcranial anatomy of Edmontosaurus regalis (Hadrosauridae) from the Horseshoe Canyon Formation, Alberta, Canada, in Evans, D.C., and Eberth, D.A., eds., Hadrosaurs: Bloomington, Indiana, Indiana University Press, p. 208-244.

Carpenter, K., Dilkes, D., and Weishampel, D.B., 1995, The dinosaurs of the Niobrara Chalk Formation (Upper Cretaceous, Kansas): Journal of Vertebrate Paleontology, v. 15, p. 275-297.

Carr, T.D., Williamson, T.E., and Schwimmer, D.R., 2005, A new genus and species of tyrannosauroid from the Late Cretaceous (middle Campanian) Demopolis Formation of Alabama: Journal of Vertebrate Paleontology, v. 25 , p. 119-143.

Conti, S., Vila, B., Sellés, A. G., Galobart, À., Benton, M. J., and PrietoMárquez, A., 2020, The oldest lambeosaurine dinosaur from Europe: 
insights into the arrival of Tsintaosaurini: Cretaceous Research, v. 107, 104286. doi: 10.1016/j.cretres.2019.104286.

Cope, E., 1866, Remarks on the remains of a gigantic extinct dinosaur from the Cretaceous Greensand of New Jersey: Proceedings of the Academy of Natural Sciences of Philadelphia, v. 18, p. 275-279.

Cope, E.D., 1869, On the reptilian orders Pythonomorpha and Streptosauria: Proceedings Boston Society of Natural History, v. 12, p. 250-266.

Cope, E.D., 1870, Synopsis of the extinct Batrachia, Reptilia and Aves of North America: Transactions of the American Philosophical Society, v. 14, p. 1-252

Dalla Vecchia, F.M., 2009, Tethyshadros insularis, a new hadrosauroid dinosaur (Ornithischia) from the Upper Cretaceous of Italy: Journal of Vertebrate Paleontology, v. 29, p. 1100-1116.

Davis, P.G., and Briggs, D.E.G., 1998, The impact of decay and disarticulation on the preservation of fossil birds: Palaios, v. 13, p. 3-13.

Ebersole, S.M., and King, J.L., 2011, A review of non-avian dinosaurs from the Late Cretaceous of Alabama, Mississippi, Georgia, and Tennessee: Bulletin of the Alabama Museum of Natural History, v. 28, p. 81-93.

Evans, D.C., and Reisz, R.R., 2007, Anatomy and relationships of Lambeosaurus magnicristatus, a crested hadrosaurid dinosaur (Ornithischia) from the Dinosaur Park Formation, Alberta: Journal of Vertebrate Paleontology, v. 27 , p. 373-393.

Everhart, M.J., 1999, Evidence of feeding on mosasaurs by the Late Cretaceous lamniform shark, Cretoxyrhina mantelli: Journal of Vertebrate Paleontology: v. 17 , p. $43 \mathrm{~A}-44 \mathrm{~A}$.

Everhart, M.J., and Ewell, K., 2006, Shark-bitten dinosaur (Hadrosauridae) vertebrae from the Niobrara Chalk (Upper Coniacian) of western Kansas: Transactions of the Kansas Academy of Sciences, v. 109, p. 27-35.

Everhart, M.J., Everhart, P.A., and Shimada, K., 1995, A new specimen of shark bitten mosasaur vertebrae from the Smoky Hill Chalk (Upper Cretaceous) in western Kansas: Abstracts with Papers Presented, 129th Annual Meeting, Kansas Academy of Science, Pittsburg, v. 14, p. 19.

Farke, A.A. and Phillips, G.E., 2017, The first reported ceratopsid dinosaur from eastern North America (Owl Creek Formation, Upper Cretaceous, Mississippi, USA): PeerJ, v. 5, e3342. https://doi.org/10.7717/peerj.3342.

Gallagher, W.B., 1993, The Cretaceous-Tertiary mass extinction event in North Atlantic Coastal Plain: The Mosasaur, v. 5, p. 75-154.

Gallagher, W.B., 1997, When Dinosaurs Roamed New Jersey: New Brunswick, New Jersey, Rutgers University Press, 176 p.

Gallagher, W.B., Parris, D.C., and Spamer, E.E., 1986, Paleontology, biostratigraphy, and depositional environments of the Cretaceous-Tertiary transition in the New Jersey coastal plain: The Mosasaur, v. 3, p. 1-35.

Gilmore, C.W., 1933, On the dinosaurian fauna of the Iren Dabasu Formation: Bulletin of the American Museum of Natural History, v. 67, p. 23-78.

Godefroit, P., Zan, S., and Jin, L., 2001, The Maastrichtian (Late Cretaceous) lambeosaurine dinosaur Charonosaurus jiayinensis from north-eastern China: Bulletin de l'Institut royal des Sciences naturelles de Belgique, Sciences de la Terre, v. 71, p. 119-168.

Godefroit, P., Bolotsky, Y.L., and Van Itterbeeck, J., 2004 Amurosaurus riabinini, a Late Cretaceous lambeosaurine dinosaur from Far Eastern Russia: Acta Palaeontologica Polonica, v. 49, p. 585-618.

Godefroit, P., Bolotsky, Y.L., and Bolotsky, I.Y., 2012a, Osteology and relationships of Olorotitan arharensis, a hollow-crested hadrosaurid dinosaur from the latest Cretaceous of Far Eastern Russia: Acta Palaeontologica Polonica, v. 57, p. 527-560.

Godefroit, P., Bolotsky, Y.L., Lauters, P., 2012b, A New Saurolophine dinosaur from the Latest Cretaceous of Far Eastern Russia: PLoS ONE, v. 7(5), e36849. https://doi.org/10.1371/journal.pone.0036849.

Hammer, Ø., Harper, D.A.T., and Ryan P.D., 2001, Paleontological statistics software package for education and data analysis: Palaeontologia Electronica v. 4, p. 1-9.

Hill, R.V., Roberts, E.M., Tapanila, L., Bouare, M.L., Sissoko, F., and O’Leary, M.A., 2015, Multispecies shark feeding in the Trans-Saharan seaway: evidence from Late Cretaceous dyrosaurid (Crocodyliformes) fossils from northeastern Mali: Palaios, v. 30, p. 589-596.

Janssen, R., Baal, R.R., and Schulp, A.S., 2013, Bone damage in Allopleuron hofmanni (Cheloniidae, Late Cretaceous): Netherlands Journal of Geosciences-Geologie En Mijnbouw, v. 92, p. 153-157.

Kobayashi, Y., Nishimura, T., Takasaki, R., Chiba, K., Fiorillo, A.R., Tanaka, K., Chinzorig, T., Sato, T., and Sakurai, K., 2019, A New Hadrosaurine (Dinosauria: Hadrosauridae) from the Marine Deposits of the Late Cret aceous Hakobuchi Formation, Yezo Group, Japan: Scientific Reports, v. 9.1, p. 1-14. doi:10.1038/s41598-019-48607-1.

Koch, R.C., and Olsson, R.K., 1977, Dinoflagellate and planktonic foraminiferal biostratigraphy of the uppermost Cretaceous of New Jersey: Journa of Paleontology, v. 51, p. 480-491.

Langston, W., 1960, The vertebrate fauna of the Selma Formation of Alabama, part VI: the dinosaurs: Fieldiana: Geological Memoirs, v. 3, p. 315-359.

Leidy, J., 1858, Hadrosaurus foulkii, a new saurian from the Cretaceous of New Jersey, related to Iguanodon: Proceedings of the Academy of Natural Sciences of Philadelphia, v. 10, p. 213-218.
Longrich, N.R., 2016, A ceratopsian dinosaur from the Late Cretaceous of eastern North America, and implications for dinosaur biogeography: Cretaceous Research, v. 57, p. 199-207.

Maidment, S.C.R., Linton, D.H., Upchurch, P., and Barrett, P.M., 2012, Limbbone scaling indicates diverse stance and gait in quadrupedal ornithischian dinosaurs: PLoS ONE, v. 7(5), e36904. https://doi.org/10.1371/journal. pone.0036904.

Mallon, J.C., Henderson, D.M., McDonough, C.M., and Loughry, W.J., 2018, A "bloat-and float" taphonomic model best explains the upside-down preservation of ankylosaurs: Palaeogeography, Palaeoclimatology, Palaeoecology, v. 497, p. 117-127.

Marsh, O.C., 1869, Notice of some new mosasauroid reptiles from the Greensand of New Jersey: American Journal of Science and Arts, v. 48 , p. 392-397.

Marsh, O.C., 1870, Remarks on Hadrosaurus minor, Mosasaurus crassidens, Leiodon laticaudus, Baptosaurus, and Rhinoceros matutinus: Proceedings of the Academy of Natural Sciences, Philadelphia, v. 1870, p. 2-3.

Marsh, O.C., 1881, Principal characters of American Jurassic dinosaurs, Part V: American Journal of Science, 3rd ser., v. 21, p. 417-423.

Martill, D.M., 1987, A taphonomic and diagenetic case study of a partially articulated ichthyosaur: Palaeontology, v. 30, p. 543-555.

McDonald, A.T., Bird, J., Kirkland, J.I., and Dodson, P., 2012, Osteology of the basal hadrosauroid Eolambia caroljonesa (Dinosauria: Ornithopoda) from the Cedar Mountain Formation of Utah: PLoS ONE, v. 7, e45712. https:// doi.org/10.1371/journal.pone.0045712.

Miller, H.W., Jr., 1956, Correlation of Paleocene and Eocene formations and Cretaceous Paleocene boundary in New Jersey: AAPG Bulletin, v. 40, p. 722-736.

Miller, K.G., Sugarman, P.J., Browning, J.V., Kominz, M.A., Olsson, R.K., Feigenson, M.D., and Hernandez, J.C., 2004, Upper Cretaceous sequences and sea-level history, New Jersey Coastal Plain: Bulletin of the Geological Society of America, v. 116, 368-393.

Morton, S.G., 1830, Synopsis of the organic remains of the Ferruginous Sand Formation of the United States, with geographical remarks: American Journal of Science and Arts, v. 17, p. 274-295.

Morton, S.G., 1834, Synopsis of the organic remains of the Cretaceous group of the United States: Philadelphia, W.B. Gibbons Printer, 88 p.

Olsson, R.K., 1963, Latest Cretaceous and earliest Tertiary stratigraphy of New Jersey coastal plain: AAPG Bulletin, v. 47, p. 643-665.

Olsson, R.K., 1989, Depositional sequences in the Cretaceous post-rift sediments on the New Jersey Atlantic margin: Marine Geology, v. 90, p. $113-118$.

Owen, R., 1842, Report on British fossil reptiles, Pt. II: Report of the British Association for the Advancement of Science, v. 11, p. 60-204.

Parks, W.A., 1919, Preliminary description of a new species of trachodont dinosaur of the genus Kritosaurus, Kritosaurus incurvimanus: Transactions of the Royal Society of Canada, ser. 3, v. 13, p. 51-59.

Parks, W.A., 1922, Parasaurolophus walkeri, a new genus and species of trachodont dinosaur: University of Toronto Studies: Geological Series, v. 13, p. 5-32.

Parks, W.A., 1923, Corythosaurus intermedius, a new species of trachodont dinosaur: University of Toronto Studies: Geological Series, v. 15, p. 1-57.

Parks, W.A., 1931, A new genus and two new species of trachodont dinosaurs from the Belly River Formation of Alberta, Tetragonosaurus praeceps, Tetragonosaurus erectofrons: University of Toronto Studies, Geological Series, v. 31, p. 1-11.

Pinna, G., 1979, Osteologia dello scheletro di Kritosaurus notabilis (Lambe, 1914) del Museo Civico di Storia Naturale de Milano: Memorie della Societa Italiana di Scienze Naturali e del Museo Civico di Storia Naturale di Milano, v. 22, p. 33-56.

Polcyn, M.J., and Lamb, J., 2012, The snout of Halisaurus platyspondylus: phylogenetic and functional implications: Bulletin de la Société Géologique de France, v. 183, p. 137-143.

Prieto-Márquez, A., 2014, A juvenile Edmontosaurus from the late Maastrichtian (Cretaceous) of North America: implications for ontogeny and phylogenetic inference in saurolophine dinosaurs: Cretaceous Research, v. 50, p. 282-303.

Prieto-Márquez, A., and Norell, M.A., 2010, Anatomy and relationships of Gilmoreosaurus mongoliensis (Dinosauria: Hadrosauroidea) from the Late Cretaceous of Central Asia: American Museum Novitates, v. 3694, p. 1-49.

Prieto-Márquez, A., Weishampel, D.B., and Horner, J.R., 2006, The dinosaur Hadrosaurus foulkii, from the Campanian of the East Coast of North America, with a reevaluation of the genus: Acta Palaeontologica Polonica, v. 51, p. 77-98.

Prieto-Márquez, A., Chiappe, L.M., and Joshi, S.H., 2012, The Lambeosaurine Dinosaur Magnapaulia laticaudus from the Late Cretaceous of Baja California, Northwestern Mexico. PLoS ONE 7(6): e38207. https://doi.org/10. 1371/journal.pone.0038207.

Prieto-Márquez, A., Dalla Vecchia, F.M., Gaete, R., and Galobart, À., 2013, Diversity, relationships, and biogeography of the lambeosaurine dinosaurs 
from the European Archipelago, with description of the new aralosaurin Canardia garonnensis: PLoS ONE, v. 8, e69835. https://doi.org/10.1371/ journal.pone.0069835.

Prieto-Márquez, A., Erickson, G.M., and Ebersole, J.A., 2016a, A primitive hadrosaurid from southeastern North America and the origin and early evolution of 'duck-billed' dinosaurs: Journal of Vertebrate Paleontology, v. 36, e1054495. https://doi.org/10.1080/02724634.2015.1054495.

Prieto-Márquez, A., Erickson, G.M., and Ebersole, J.A., 2016b, Anatomy and osteohistology of the basal hadrosaurid dinosaur Eotrachodon from the uppermost Santonian (Cretaceous) of southern Appalachia: PeerJ, v. 4, e1872. https://doi.org/10.7717/peerj.1872.

Roemer, F., 1849, Texas, mit besonderer Rücksicht auf deutsche Auswanderung und die physischen Verhältnisse des Landes nach eigener Beobachtung geschildert; mit einem naturwissenschaftlichen Anhange und einer topographisch-geognostischen Karte von Texas: Bonn, Adolph Marcus, $464 \mathrm{p}$.

Say, T., 1820, Observations on some species of Zoophytes, shells, etc. principally fossil: American Journal of Science, and Arts, v. 2, p. 34-45.

Schein, J.P., and Poole, J.C., 2014, A shark-bitten dinosaur (Hadrosauridae) femur from the latest Maastrichtian Basal Hornerstown Formation, New Jersey, U.S.A.: The Mosasaur, v. 8, p. 15-22.

Schwimmer, D.R., 1997, Late Cretaceous dinosaurs in Eastern USA: a taphonomic and biogeographic model of occurrences, in Wolberg, E., and Stump, E., eds., Dinofest International Proceedings: Philadelphia, Philadelphia Academy of Natural Sciences, p. 203-211.

Schwimmer, D.R., 2002, King of the Crocodylians: The Paleobiology of Deinosuchus: Bloomington, Indiana, Indiana University Press, 220 p.

Schwimmer, D.R., Williams, G.D., Dobie, J.L., and Siesser, W.G., 1993, Late Cretaceous dinosaurs from the Blufftown Formation in western Georgia and eastern Alabama: Journal of Vertebrate Paleontology: v. 67, p. 288-296.

Schwimmer, D.R., Stewart, J.D., Williams, G.D., 1997, Scavenging by sharks of the genus Squalicorax in the Late Cretaceous of North America: Palaios, v. 47 , p. 71-83.

Seeley, H.G., 1888, On the classification of the fossil animals commonly named Dinosauria: Proceedings of the Royal Society of London: v. 43, p. 165-171.

Senter, P., 2012, Forearm orientation in Hadrosauridae (Dinosauria: Ornithopoda) and implications for museum mounts: Palaeontologia Electronica, v. 15,$3 ; 30 \mathrm{~A}, 10$ p. https://palaeo-electronica.org/content/2012-issue-3articles/324-hadrosaurid-forearm.

Shimada, K., and Everhart, M.J., 2004, Sharkbitten Xiphactinus audax (Teleostei: Ichthyodectiformes) from the Niobrara Chalk (Upper Cretaceous) of Kansas: The Mosasaur, v. 7, p. 35-39.
Shimada, K., and Hooks, G.E. 2004. Shark-bitten protostegid turtles from the Upper Cretaceous Mooreville Chalk, Alabama: Journal of Paleontology, v. 78 , p. $205-210$.

Syme, C.E., and Salisbury, S.W., 2014, Patterns of aquatic decay and disarticulation in juvenile Indo-Pacific crocodiles (Crocodylus porosus), and implications for the taphonomic interpretation of fossil crocodyliform material: Palaeogeography, Palaeoclimatology, Palaeoecology, v. 412, p. 108-123.

Tsogtbaatar, K., Weishampel, D.B., Evans, D.C., and Watabe, M., 2019, A new hadrosauroid (Dinosauria: Ornithopoda) from the Late Cretaceous Bayenshire Formation of the Gobi Desert (Mongolia): PLoS ONE, v. 14, e0208480. https://doi.org/10.1371/journal.pone.0208480.

Tuomey, M., 1856, Description of some new fossils from the Cretaceous rocks of the southern States: Proceedings of the Academy of Natural Sciences of Philadelphia, v. 7, p. 167-172.

Vavrek, M.J., Hills, L.V., and Currie, P.J., 2014, A hadrosaurid (Dinosauria: Ornithischia) from the Late Cretaceous (Campanian) Kanguk Formation of Axel Heiberg Island, Nunavut, Canada, and its ecological and geographical implications: Arctic, v. 67, p. 1-9.

Weishampel, D.B., 2006, Another look at the dinosaurs of the East Coast of North America, in 'Coletivo Arqueológico-Paleontológico Salense, eds., Actas III Jornadas Dinosaurios Entorno: Burgos, Spain, Salas de los Infantes, p. 129-168.

Weishampel, D.B., and Young, L., 1996, Dinosaurs of the East Coast: Baltimore, Johns Hopkins University Press, 275 p.

Weishampel, D.B., Barrett, P.M., Coria, R.A., Loeuff, J.L., Xing, X., Xijin, Z., Sahni, A., Gomani, E.M.P., and Noto, C.R., 2004, Dinosaur Distribution, in Weishampel, D.B., Dodson, P., and Osmólska, H., eds., The Dinosauria, 2nd Ed.: Berkeley, University of California Press, p. 517-617.

Weishampel, D.B., Sartin, C.E., and Nabavizadeh, A., 2012, Hadrosaurids from the 'lost continent' of Appalachia: Society of Vertebrate Paleontology Annual Meeting Abstracts, p. 192A.

Wilson, M.A., 2007, Macroborings and the evolution of marine bioerosion, in Miller, W., III, ed., Trace Fossils: Concepts, Problems, Prospects: Amsterdam, Elsevier Scientific Publishing Co., p. 356-367. DOI: 10.1016/ B978-044452949-7/50146-7

Zangerl, R., 1953, The vertebrate fauna of the Selma Formation of Alabama. Part 3. The turtles of the family Protostegidae. Part 4 . The turtles of the family Toxochelyidae: Fieldiana, Geology Memoirs, v. 3, p. 61-277.

Accepted: 30 August 2020 